\title{
2. The BBC's Children in Need Telethon: The Currencies of Compassion
}

\author{
Karen Lury
}

\begin{abstract}
This chapter illustrates how the BBC's Children in Need telethon is informed and legitimated by different currency models as part of its aesthetic strategy. It demonstrates how these televisual currencies may be directly aligned with other kinds of medical currency models emerging within the economy of the UK's National Health Service. Through close textual analysis of the programme and a related analysis of medical currency models proposed and piloted in relation to the NHS, it is argued that the 'aestheticization' of currency models provided by the programme reflects an ideological shift in the representation of medical care on public service television, in line with the ideology of neoliberalism and the incremental colonization of 'financialization' into all aspects of contemporary society.
\end{abstract}

Keywords: telethon; financialization; currency models; charity; child/ children; textual analysis; public service television; campaign film; Children in Need

What follows is a brief description of a fifteen-minute sequence from the live broadcast of the Children in Need telethon, first transmitted at approximately 9.30 p.m. on British Broadcasting Corporation 1 (BBC1) on Friday 13 November 2015. This is an annual broadcast for the benefit of children who are ill, disabled, or living in poverty.

The colours in the television studio theatre are luminous - the predominant colour scheme is made up of purples, pink, and gold-and, at the start of this sequence, the television camera pans rapidly in, over a seated, cheering audience, to focus in on the presenters, Dermot O'Leary and Fearne

Bonah, C. and A. Laukötter (eds.), Body, Capital, and Screens: Visual Media and the Healthy Self in the 2oth Century. Amsterdam: Amsterdam University Press, 2020 DOI 10.5117/9789462988293_CHO2 


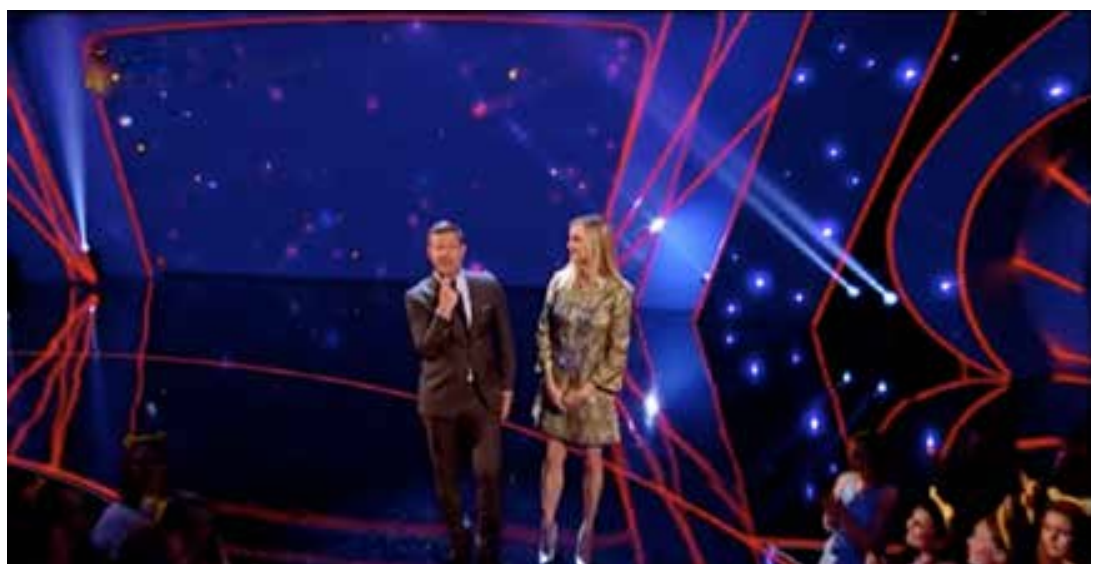

2.1. Dermot O'Leary and Fearne Cotton, Children in Need, 13 November 2015, BBC1.

Cotton (Figure 2.1). ${ }^{1}$ They stand at the front of the stage, speaking both to the in-studio audience and the viewing audience at home. Framed by two large video screens, they are dressed formally-Dermot in a designer leisure suit and Fearne in a sparkly special occasion dress. Pausing to make a short, improvised joke in which they poke gentle fun at the presenter of the previous live segment, the actor Shane Richie, Dermot and Fearne then direct the viewers' attention to the next segment, a live outside broadcast. ${ }^{2}$ In this heavily trailed stunt, the BBC's Radio 1 presenter, Scott Mills, will abseil from the top of the ArcelorMitall Orbit - a huge, red, metal structure, designed by Anish Kapoor, and one of the few landmarks remaining from the London 2012 Summer Olympics. Supported by another well-known children's television presenter and 'action woman', Helen Skelton, Mills successfully completes the abseil. ${ }^{3}$ The event culminates with cheers from a small crowd of spectators at the scene and an explosion of fireworks as Mills reaches

1 Dermot is a television presenter no doubt familiar to millions from the United Kingdom's version of The X-Factor and, previously, the reality show, Big Brother. Fearne Cotton has been on British television since she was a teenager, initially presenting The Disney Club on the commercial channel Good Morning Television (GMTV) and later presenting the BBC's now-defunct popular music programme, Top of the Pops.

2 Richie, who is well known on British television as both an actor and presenter, had been fronting celebrity interviews from the 'Queen Vic' - the fictional public house well known from its location within the heart of Albert Square and the 'home' of the BBC's long-running soap opera Eastenders. In the soap opera, the Queen Vic pub was once owned and run by Richie's character, 'Alfie Moon'.

3 Skelton is well known in the UK context from her appearance on the BBC's long-running children's show Blue Peter and is regarded commonly as an action woman for her successful completion of various adventurous stunts, some of which were for another charity telethon also 
the ground. The tension and excitement that is generated for the television audience by this stunt is amplified by the added (non-diegetic) sound of tense, rhythmic music and the rapid cutting of a series of close-up shots of Scott's open-eyed expressions of fear, interspersed with an additional series of quick cut-aways to Skelton, who offers breathless and enthusiastic support. Throughout the stunt, a ribbon videographic runs across the bottom of the television screen, urging viewers to 'Support Scott' by donating money to Children in Need. Once the abseil is completed, the programme returns to the studio, with both Dermot and Fearne warmly congratulating Mills for his bravery and applauding his endeavour as a significant part of the evening's fundraising. The next segment is then introduced by both presenters who are now framed in a mid, rather than long shot, and who stand directly in front of one of the video screens. While suggesting that the next film is 'incredibly sad', they urge viewers 'to please stay with us' as the well-known Scottish actor David Tennant is about to introduce us to an 'incredible couple' who have suffered a terrible loss. This introduction then leads to a short campaign film, made about Robin House - a children's hospice in Scotland — which details the medical history and deaths of two young children, although it is the support offered by the hospice to their parents that is the focus of the film. When we return to the television studio, Dermot is standing alone by a video screen with his arms crossed and his hand to his mouth. His voice cracks with emotion when he states that, as he was only asked 'at the last minute' to stand in for the regular presenter of the telethon, this means that he-like the television viewer-'had not seen the film until this evening' and that he is seeing these scenes 'as you see them at home'. Seemingly on the verge of tears, he once more commends the 'incredible couple' featured in the film for their bravery, and he urges the viewing audience, once again, to donate, reading out the direct telephone line and the internet address for charitable donations, which are now displayed on the screen behind him (Figure 2.2). He then directly hands over to Fearne, who is standing some distance away, at the centre of the stage. At first, she speaks in a serious tone, reflecting the intense emotion previously expressed by Dermot. However, as she continues and introduces the next segment, which will bring into the studio the celebrities and children involved in another extended stunt - the 'Rikshaw Challenge' - she allows the excitement in her voice to overcome her initial sombre tones, and her intonation rises when she warmly introduces another pre-recorded video sequence, in which each of the 'inspirational' 


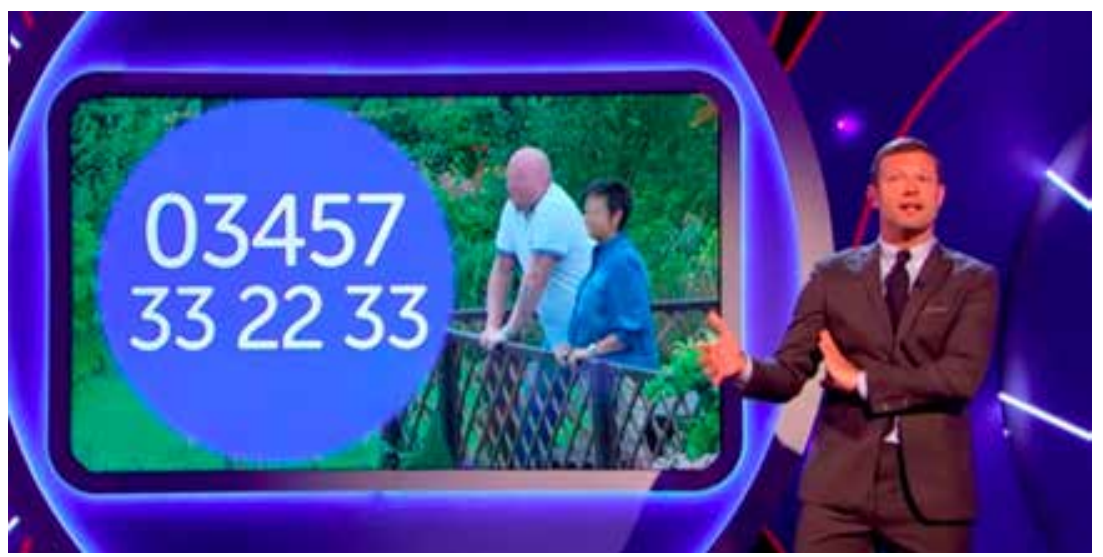

2.2. Dermot O'Leary, Children in Need, 13 November 2015, BBC1.

young riders involved in the challenge are identified, all of whom have, she observes, previously been supported by projects 'funded by Children in Need'.

This sequence is not exceptional. As a television broadcast, the programme, which has been running for over 35 years, is both familiar and predictable for British audiences, and, as such, it is frequently regarded by critics and perhaps by many of the television audience as banal. Yet, its incorporation of the live and recorded, the serious and silly, and the necessary emotional turbulence this engenders, actually suggests this is a programme of extraordinary complexity. It is certainly controversial, as this conflicted response from a reviewer for the The Guardian newspaper suggests:

Children in Need might be hard to sit through. Usually that's the whole point - as a television programme, it exists purely to destabilise you with such an unrelenting volley of conflicting emotions that you end up flinging money at it in a kind of sobbing fugue state. ${ }^{4}$

Children in Need - as its title suggests - provides funds for a variety of different children's charities, many of which are involved in the care and support of severely ill children and their families. Originating in 1927, via an annual radio appeal, it was initially broadcast by the BBC on Christmas Day. Christmas, of course, represented a suitably emotive and appropriate time for such an appeal. It is a particularly resonant period within the British context, as it is so closely aligned with the Dickensian framing of 
Christmas as a time for charity and inclusive good deeds. The figure of 'Tiny Tim' from the Dickens's novella A Christmas Carol (1843), looms large in the popular imagination, as a concrete representation of the 'deserving sick' and the poignant figure of the plucky, yet tragically disabled child. From the 1970s, the appeal was led by the BBC's hugely popular radio and television personality, Sir Terry Wogan. A move to a telethon format in 1980 seems to have been, in part, a response to the transmission of a successful charity telethon from a rival independent broadcaster within the London area, Thames Television. ${ }^{5}$ Children in Need is now usually scheduled by the BBC for the third Friday in November - so, whilst it is no longer scheduled on Christmas day itself, its place in the calendar means that it has become established as a kind of secular advent to the BBC's Christmas season of television programming. ${ }^{6}$

The Children in Need programme, like other telethons, is an evening-long event, incorporating a variety of celebrity sketches and musical performances. Its format differs slightly from other telethons as it devotes a lot of screen time to illustrating the fundraising efforts of the 'great British public'7 as well as focussing on a variety of stunts associated with different BBC programmes (e.g. The One Show's 'Rikshaw Challenge') and radio channels (e.g. Scott Mills's abseil and BBC Radio 2's celebrity auctions.) These fundraising events — whether by celebrities or 'ordinary people' - are often humorous in nature, involving dressing up, or may otherwise be regarded as 'silly' (such as the waxing of male chest and leg hair, or when $\mathrm{BBC}$ newscasters attempt a song and dance routine). Alternatively, stunts can

5 North American television has also been broadcasting charity telethons since the 1960s, the best known of which is the Muscular Dystrophy Association (MDA) telethon presented by the comedian Jerry Lewis. For more on the US version of the charity telethon, see Longmore, Telethons.

6 Wogan presented the BBC's telethon for 35 years but, in 2015, he was forced to pull out at short notice due to ill health, and Dermot O'Leary was the main host for that year. Wogan died in January 2016 and, from November 2016, Children in Need has presented a 'fundraiser of the year award' in Wogan's name. Now led by another experienced and popular presenter/broadcaster, Graham Norton, the live programme and associated events continue to raise large amounts of money-over $£ 50$ million in 2017.

7 The 'great British public' is a commonly used term relating to national identity; frequently employed by British television presenters and politicians, it refers to the notion that, in times of crisis, the 'British public' will act together for the greater good. In popular memory, this is largely associated with the apparent response to the 'Blitz' bombing of cities in the Second World War. In recent tabloid newspaper reporting, the 'great British public' has re-merged as a way of eulogizing the public's response to terrorist events. An amusing analysis of the term is presented by the British comedian David Mitchell: https://www.youtube.com/watch?v=SdVnEbHZjzo, accessed 24 July 2018. 
be endurance- or challenge-orientated, including dares (parachute jumps, abseils), sponsored walks, runs, or silences. In many of these activities, fundraising is associated with exhibiting or testing the fundraiser's own body, so that the activity of the fundraiser and, by implication, the television audience, is not simply to donate money but to make themselves (temporarily) exceptional, visible, and active. Such exhibitionism is, of course, appropriate for a charity that needs to secure content that is entertaining, but, in a more complicated sense, the fundraisers' bodily alignment with the 'vulnerable bodies' of the 'children in need' is also significant. Children who are to be recipients of the donations may be seen to be exceptional through their visible disabilities and medical histories; equally, they may be understood to represent endurance or face significant challenges through their suffering, whether this is a result of accident, illness, or economic deprivation. As a result of their fundraising exertions, able-bodied children and adult fundraisers may also experience and exhibit either (temporary) exceptionality or undergo challenges and feats of endurance, suggesting that the donors and recipients of the charity are, at least briefly, aligned. ${ }^{8}$ Indeed, the emphasis on participation and the relationship between 'us' (donors) and 'them' (as recipients) has become increasingly blurred by the inclusion of disabled children who participate in the 'Rikshaw Challenge' and, from 2016, by the presence of Ade Adepitan, a television personality and Paralympic sportsperson, as one of the co-presenters for the in-studio broadcast. While the increasing visibility and participation of disabled presenters and children in the broadcast may be seen positively (in terms of representation and agency) it nonetheless obscures the self-exploitation inherent to the programme. From this perspective, the programme presents a rather unfortunate coincidence in which disabled or 'needy' children provide their labour - free of charge - to raise funds they themselves need. As such, they are not only representatives of the deserving poor or sick ('Tiny Tims') but are asked to perform or establish their (monetary) value to the television audience.

Despite its wide-ranging and, frankly, rather peculiar content, in the context of UK public-service broadcasting, Children in Need is as much

8 The alignment of the fundraisers' and recipients' bodies is similar to the 'productive turn' described by Timm Knudsen and Stage in Global Media. However, aspects of their argument suggest that that this 'productive turn' is largely beneficial for those involved. As will become evident, I am less certain that these 'new constellations' really offer new possibilities and agree with their more cautious conclusion that 'the accusations of narcissism that are levelled at all forms of charity are not refuted once and for all by the productive turn'; Timm Knudsen and Stage, Global Media, p. 85 . 
a part of the annual British 'broadcast calendar' as the Wimbledon Tennis Championships or the opening of Parliament. In terms of charitable programming in the UK, it is similar to, and, in terms of celebrity activity and international profile, possibly overshadowed by other charity broadcasts such as Comic Relief. ${ }^{9}$ Channel 4 has also, since 2012, screened another regular telethon, Stand Up to Cancer..$^{10}$ Children in Need therefore appears as one among several different kinds of charity programmes on British television. It differs from other British telethons, in part, because of its longevity-Comic Relief has only been running biannually since 1985 and Stand Up To Cancer had its first broadcast in 2012-but it is also unique in the exclusive focus on children and its provision of funds only for children from the UK. The appeal to the viewer in terms of empathy and compassion is therefore not in relation to the 'distant other' or the starving child familiar from a range of international charity appeals, nor does it ask for medical research funding, which is the primary focus of Stand Up to Cancer. ${ }^{11}$ Rather, the Children in Need (previously Children in Need of Help) appeals for British children who are impoverished, or who may be suffering from a range of medical or psychological challenges, including bereavement, mental illness, physical disability, or serious life-limiting conditions. The complex needs of the children and the various services they are dependent on mean that many of the children are recipients, not just of charitable support, but a variety of different medical services. The charity and the broadcast itself are therefore implicated in the complex evolution of the British care system and related medical provision offered by the UK's National Health Service (NHS).

The purpose of this chapter is to illustrate how the programme is informed and legitimated by different currency models and to demonstrate how these televisual currencies may be directly aligned with other kinds of currency models emerging within the economy of the NHS. The use of the term currency here adapts contemporary sociological theories, which argue that everyday life is now increasingly determined by the way in which social and emotional practices — in this instance, medical care, sentimental

9 Comic Relief is a private charity, founded in 1985 by the British film-maker and writer Richard Curtis, as a response to the huge success of Band Aid/Live Aid in 1984/1985. While Comic Relief and its associated 'sister charity' Sports Relief are both regularly broadcast on the BBC they—unlike Children in Need - are not part of the BBC itself. While both Comic Relief and Sports Relief provide some funding for UK charities and groups, much of the funding is focussed, like Band Aid/Live Aid, on international concerns. For more information, see their website https:// www.comicrelief.com, accessed 25 July 2018.

10 For more on Stand Up to Cancer, see Charlesworth, 'Stand Up to Cancer'.

In relation to the concept of the 'distant other', see Boltanski, Distant Suffering. 
valuation, and philanthropy_-are being assigned numerical values, and, in a related manner, embedded into the processes of 'financialization'. As Catherine Happer explains, the concept of financialization not only describes the current political economy as shaped by financial markets, but it also "incorporates an emphasis on the "naturalisation" of finance and [...] refers to the way in which aspects of everyday experience are quantified and interpreted in financial terms.' ${ }^{\prime 2}$

In any national context, medical care obviously depends upon financial systems and budgets in order to operate: However, my concern here is the way in which the UK's system - the NHS - whose constitution confirms that the system is comprehensive and, in most instances, 'free at the point of use', increasingly organizes and legitimates budgetary decision-making in relation to the principles of financialization. The 'naturalization' of financialization that Happer refers to is an ideological shift within the larger context of neoliberalism and is, I suggest, unsurprisingly mirrored in different aspects of the television broadcast which has had long-term and substantial links both to a range of different private charities and to the NHS itself. Whilst I am not claiming that there is deliberate collusion here, what could be understood as the programme's 'aestheticization' of financialization reflects an ideological shift that may have real consequences for the British public's perception as to how and why decisions are legitimated in relation to the resources made available for a range of medical and social needs.

There are a variety of ways in which currency models operate both within and alongside the broadcast.

1. Television viewers' donations of money are the most explicit way in which currency (in the form of pounds donated and raised) is made visible. As is customary in the telethon, throughout the evening, these donations are represented by a running total — a 'totalizer' - that is displayed and announced at key points in the programme. The totalizer establishes that the stunts and skits produced by celebrities and ordinary people are effectively paid for - the labour of the participants is given a specific and visible monetary value (Figure 2.3 ). ${ }^{13}$

12 Happer, 'Financialization', p. 438.

13 This aspect of the programme is perhaps not as explicit now as it was in the earlier years of the programme's history. However, the crude nature of this exchange can be seen in a stunt that was replayed in the Children in Need: 50 Greatest Moments - a special programme of highlights from the different broadcasts that was screened in 2010 to celebrate the show's zoth anniversary. In the clip, from 1983 - in a stunt that is framed as Wogan's particular 'favourite'-Joanna Lumley (a well-known British actor/presenter) volunteers to 'take her dress off' if money is pledged to 


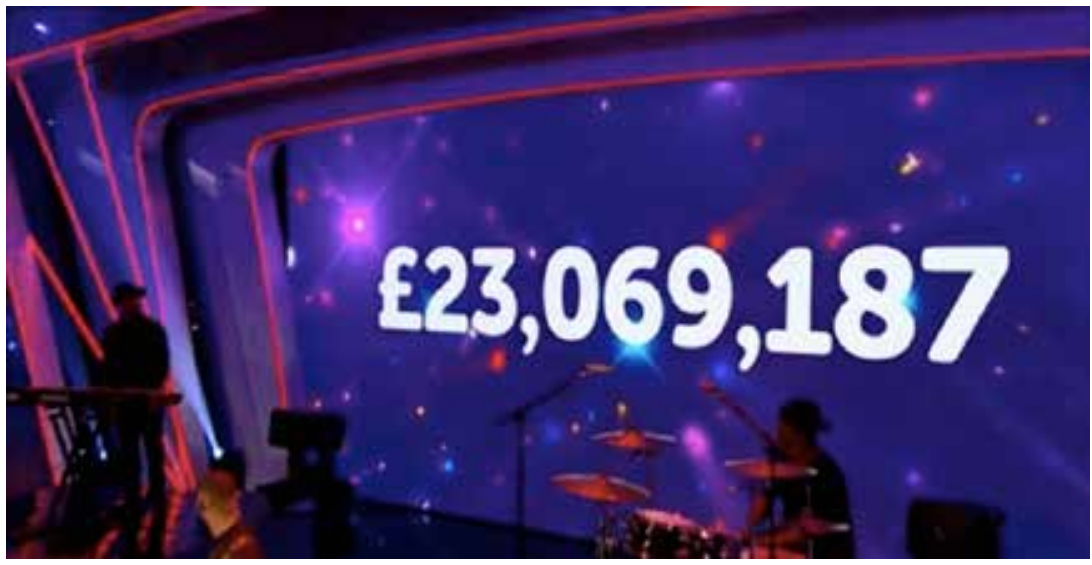

2.3. The 'Totalizer', Children in Need, 13 November 2015, BBC1.

2. Elsewhere within the programme, a currency of sorts can also be recognized as the manifestation of the (usually less than explicit) contract between the BBC and its national audience, in which the illusion of a 'nation' - a holistic, caring entity - is self-consciously generated and sustained by the programme's continued attempts to include as many different regions and individuals as possible. This is significant because it allows the BBC not only to defend and sustain the concept of 'one nation', but also to align this concept, and thus the BBC, with the NHS as a highly valued institution and as part of the make-up of a British national identity. ${ }^{14}$

3. Within the campaign films, the repetition of a familiar narrative structure establishes that there is another kind of currency at work in the programme. Each film organizes segmented instances of heightened emotional content to derive a specific monetary response (a donation) from the viewing audience. As I will explain, these moments within the films may be directly compared to Laura Grindstaff's conception of the 'money shot' in other genres of film and television. ${ }^{15}$

4. Another relevant model of currency exists outside the broadcast itself, and relates to financial planning within the NHS. This currency is

the programme. As the clip later reveals, enough money appears to be donated and she duly strips to her underwear on camera.

14 The sacrosanct status of the NHS within British national identity is very much a focus of contemporary media coverage, and its place within a shared 'national fantasy' was also made evident by its presence in the opening ceremony for the 2012 Olympic Games. See Bryant, 'National Art'.

15 See Grindstaff, Money Shot. 
dependent on the recorded data of individual medical needs, which are then rationalized and calculated as numerical values ('health care units'). These 'health care units' as currency may then be employed as a way to forecast and rationalize healthcare funding for patients, including children with life-limiting conditions.

Thus, within the programme and in the provision of healthcare in the UK, these different kinds of currency establish an economy through which the dying and deaths of children may be assigned a specific monetary value. In effect, representations of dying and dead children function for these currencies as their 'gold standard'. ${ }^{16}$

\section{The BBC's Currency: One Nation = One BBC}

The Children in Need charity's staff are BBC employees but they are not programme makers. Whether the BBC's production teams who make the campaign films, or who supervise the live broadcast at the various regional centres, are paid for their labour is undisclosed. However, the charity's website states clearly that the celebrities and professional hosts are not paid for their work, although the programme must provide an opportunity to raise profiles and publicize forthcoming films, programmes, and music. As an umbrella organization, Children in Need does not run any charitable activities itself; rather, it awards grants and support to a wide range of other smaller charities across the UK, in the 'name of the BBC'. The charity thus has a national status but allocates money locally. In that sense, it reflects the broadcasting model of the BBC itself. It offers a specific example of how local provision (such as television for regional audiences) may be embedded in a national broadcast, asking audience members to recognize themselves as both 'local' and 'national'. As a public-service broadcaster, the BBC is still currently funded by a universal licence fee paid by everyone in the UK who accesses BBC content either through television screens or via digital platforms. This means that, in order to sustain its financial position, the BBC must constantly negotiate and reaffirm its position and value as a national broadcaster but, at the same time, remain sensitive to diversity and the various individuals within the regions and nations that make up its audience.

16 The 'gold standard' refers to the now-abandoned financial system through which individual currencies were valued - or guaranteed — in relation to each other via the price of gold. 
In a 1986 report on the programme (commissioned by the BBC's Director of Public Affairs), the authors, Geoff Buck and Johnny Wilkinson, make two key comments that reinforce how this mixture of the local and national makes the programme particularly significant for the BBC. Commenting on the benefits for the $\mathrm{BBC}$, they reflect on the way in which the programme enables the $\mathrm{BBC}$ to bring the 'network' (that is the London centre of operations) and the regions and 'nations' (BBC Wales, Scotland, and Northern Ireland) together, suggesting: 'It was indeed an occasion in which all parts of the BBC domestically were involved, and normal territorial distinctions were forgotten.' ${ }^{\prime 7}$

At the same time as bringing the various parts of the $\mathrm{BBC}$ together, the report argues that the programme also serves as a live event that could bring together the viewing audience as a national community-perhaps suggesting it was an occasion in the British context that could only be matched by a royal wedding. The conclusion of the Director of Public Affairs (DPA) report suggests:

The importance of the appeal from a social point of view cannot be overestimated. People throughout Britain, who do not belong to a church, a political party, or a national or local organisation, can get involved and identify with it as individuals and feel part of a national community. ${ }^{18}$

This national community is still very much evoked in the contemporary programme - for example, a regular stunt is the children's choir, in which groups of children across the United Kingdom are brought together at different regional production centres and sing together 'live' so that one song bridges the transition to the different children at different locations across the various parts of the country - from Wales, to Scotland, to the North East and Northern Ireland. The apparent technological and operational challenge this presents, with its successful execution clearly dependent on all the different production personnel in the different $\mathrm{BBC}$ regions working together, pays dividends both for the reputation of the BBC - revealing it to be a national and expert broadcaster — as well as for the community-building aspect of the programme itself. ${ }^{19}$

17 Buck and Wilkinson, 'Report', p. 5 .

18 Buck and Wilkinson, 'Report', p. 3.

19 This practice - an attempt by the BBC to construct an imaginary 'national community' - is obviously very much in line with Benedict Anderson's notion of the nation as an 'imagined community'; see Anderson, Imagined Communities. 


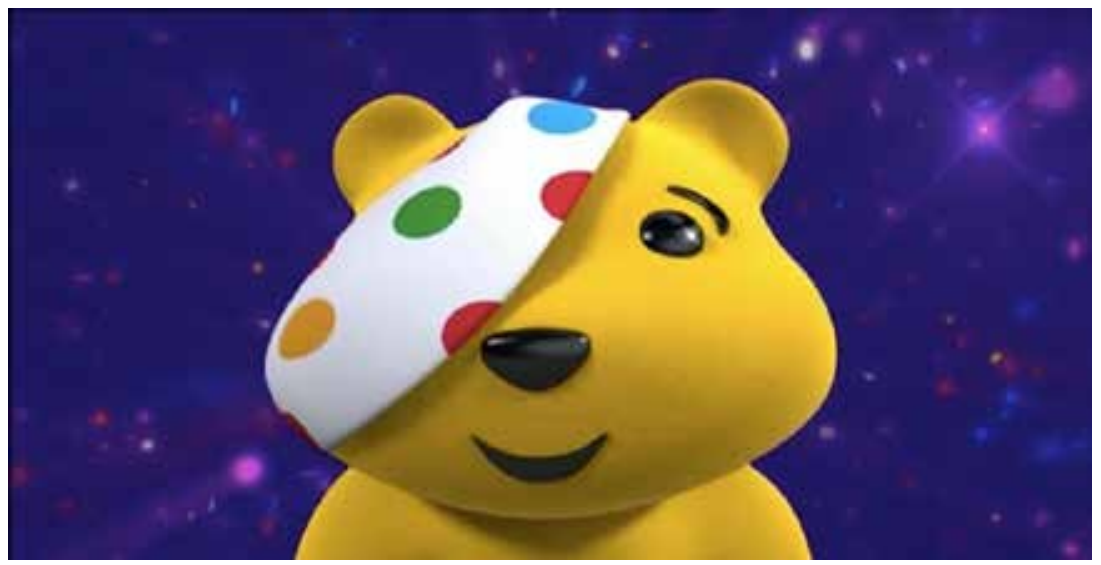

2.4. Pudsey, Children in Need, 13 November 2015, BBC1.

Yet, in practice, the relationship between the network and regions and nations has often been more problematic. In the BBC Archives, a considerable number of papers demonstrate the way in which other parts of the BBC felt that they were excluded or marginalized by the demands of the producers in London.

In a letter to Keith Clements, who was then Head of Broadcasting at the BBC, John Adams, the Scottish producer of Children in Need in 1990, comments on the mismanagement of what was clearly meant to be a nationally unifying stunt — a series of different instances in which the 'Pudsey special' (Figure 2.4), a train travelling over the course of one day, beginning in Edinburgh (Scotland) to Cardiff (Wales) would climax with the arrival of the train at Paddington in London in the evening. ${ }^{20}$

My AFM (Assistant Floor Manager) tells me that it took as much effort to organise the departure of the train and its brief stop in Edinburgh as it did to organise the rest of the events that evening. She and many others worked 21 1/2 hours that day beginning at $05 \cdot 30$. But should we have asked severely disabled kids to get out of their beds at 04.30 just to get on a train to be paraded before the camera? We certainly got a good one-and-half minute piece of it which we showed early in the evening.

20 'Pudsey' - a yellow teddy bear — has been the trademark 'mascot' of the charity since the mid 1980 s. He can be seen throughout the programme either as someone dressed in a 'Pudsey' costume or as an animated character. Different kinds of Pudsey merchandise-T-shirts, headbands, and small teddy bears — are also available from October each year in stores around the UK and online. 
The failure, however, of the arrangements to send a package from the train PSC crew from Cardiff down the line to London meant that the rest of the UK did not see the start or the passage of the train, only its arrival in Paddington. And it was the arrival of the train that threw the 22.45 opt out; so, I think questions have to be asked about the wisdom of that whole enterprise. ${ }^{21}$

Initially, as this quotation suggests (with its reference to the 'opt out' meaning a return to the BBC Scotland live broadcast at 22.45), earlier versions of the broadcast programme incorporated extensive live coverage from what might be understood as 'the national within the national' broadcasters (such as Wales, Northern Ireland, and Scotland but not smaller regions such as the Midlands). In Scotland, the majority of the broadcast time for the first 30 years of the programme's history was managed locally, with a return to the 'network' (or the London studio) only occurring for high-profile celebrity performances and sketches. However, as the quote above suggests, this was difficult to manage and caused increased friction, rather than enhancing the relationship between the BBC's 'territories'. It is perhaps not surprising that, from 2010, the programme reverted to a model in which the majority of the programme is broadcast and managed from London, with shorter segments produced by its regions/nations. Thus, despite the programme's attempt to be 'inclusive' and incorporate activities across the nation, production constraints mean that the London operation remains dominant, going against the grain of the BBC's recent attempts to diversify and 'spread' its production base. ${ }^{22}$ In recent programmes, such as the 2015 broadcast, attempts to re-establish some sense of this diversity were reflected in the way in which aerial shots were used in interstitial sequences to emphasize how different towns and regions are all included in the fundraising activity (Figure 2.5).

Despite the ultimate dominance of the London-based production studio and personnel, the programme continues to present a very careful managing and orchestration of diversity, locality, and identity in terms of image and representation. In doing so, it establishes the illusion of a national caring community, which simultaneously sustains the illusion of a national viewing audience. This is particularly useful to the BBC within a contemporary

21 Letter from Johan Adams to Keith Clements (1 January 1990), BBC Written Archives' Centre, archive ref: SC140/1041/1 (26348109).

22 For example, the BBC moved its production of Sports, Children's, and Breakfast television to Salford (near Manchester) in 2011. 


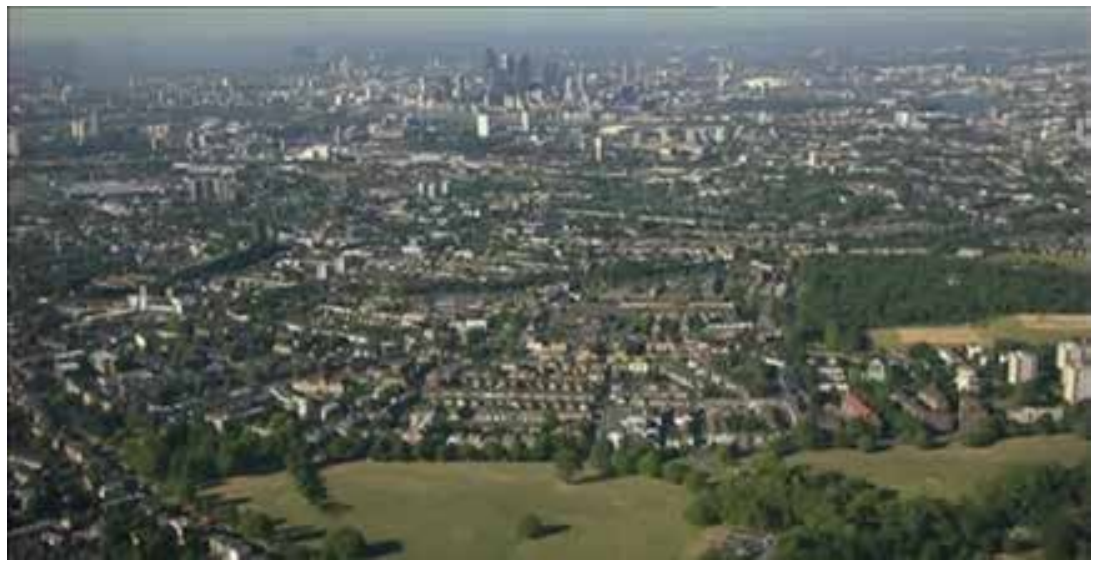

2.5. 'From Morecambe to Milton Keynes', image from interstitial sequence, Children in Need, 13 November 2015, BBC1.

context in which television programming and audiences are increasingly spread across numerous digital platforms and independent providers. The continuing success of the programme sustains an illusory national audience, and thereby shores up the currency that underpins the financial basis for the BBC.

Confirming the $\mathrm{BBC}$ as a national institution promotes its strong alliance with what is often regarded as its sister institution, the UK's National Health Service. And, like the BBC, while the NHS is still attempting to provide universal provision for all, it offers quite different kinds of medical care locally and intra-nationally. For example, a recent focus of newspaper headlines has been the emergence of what has been called a 'postcode lottery' - a term referring to the fact that certain kinds of care may only be offered in particular parts of the country. ${ }^{23}$ As the development and increasing utilization of a 'health care currency' demonstrates, funding for particular kinds of health provision are rationalized to local, and increasingly personalized, models of healthcare funding. In relation to Children in Need, the national audience conjured into existence via the broadcast generates the illusion of a national community and a nation state, which allocates funding on the basis of 'need'. This operates within a particular context in which the needs of the child-because of the child's apparently sacrosanct status in current political and social discourses—comfortably supersedes the needs of other (here invisible) individuals, such as the elderly, even though, in many instances, the entanglement of intergenerational care, 
for both young children and ageing (grand)parents, is a central aspect of many families' experiences.

This sleight of hand causes some issues for the programme. As indicated, several of the charitable organizations included by the programme are the children's hospices and their films, which necessarily focus on the stories of severely ill, dying children. These films provide some of the most compelling content and depict some of the most deserving recipients of charity. However, while their campaigns are usefully emotive and dramatic, their recognized 'value for money' - that is, the return on the money invested in terms of emotional or sentimental recompense for the viewer-is such that it might be a surprise for the audience to learn that children's hospices are not entirely funded by the NHS and are, in fact, institutions largely funded via charitable donations. For example, the hospice featured in a 2015 campaign film - Robin House (part of the children's charity, Children's Hospice Association Scotland) - currently receives approximately 19 per cent of its funding from the NHS, including some smaller grants for specific activities from the Scottish government. ${ }^{24}$ Although Dermot does explain to viewers that Robin House is dependent for 70 per cent of its financing from charitable donations, in the short film about the hospice, what is and isn't funded by these charitable donations is not clearly explained, as this would obviously distract the audience from the individual stories of the children and the film's intent to generate pathos and sentiment in the viewer. In relation to the overarching ethos of the programme, too much information regarding what is and isn't funded would also impact the meaning and integrity of the gratitude expressed by the celebrities, presenters, families, care workers, and children throughout the evening (Figure 2.6). If the thanks they express were more overtly understood to be, in part, for activities and actions that are or should be supported by the NHS - which is funded through taxation - then this would undermine the integrity of the programme. This is because the programme depends upon the notion of charity, as a series of individual and temporarily collective actions, as an acceptable mode of funding for those most in need. By directing the audience's attention away from the evolving patchwork of state and philanthropic funding that is the reality of social care and healthcare provision in the UK, the programme avoids representations of 'children in need' that might be regarded as political.

24 For figures related to NHS funds (restricted) and charitable funds, see Children's Hospice Association Scotland, Annual Report, p.16. 


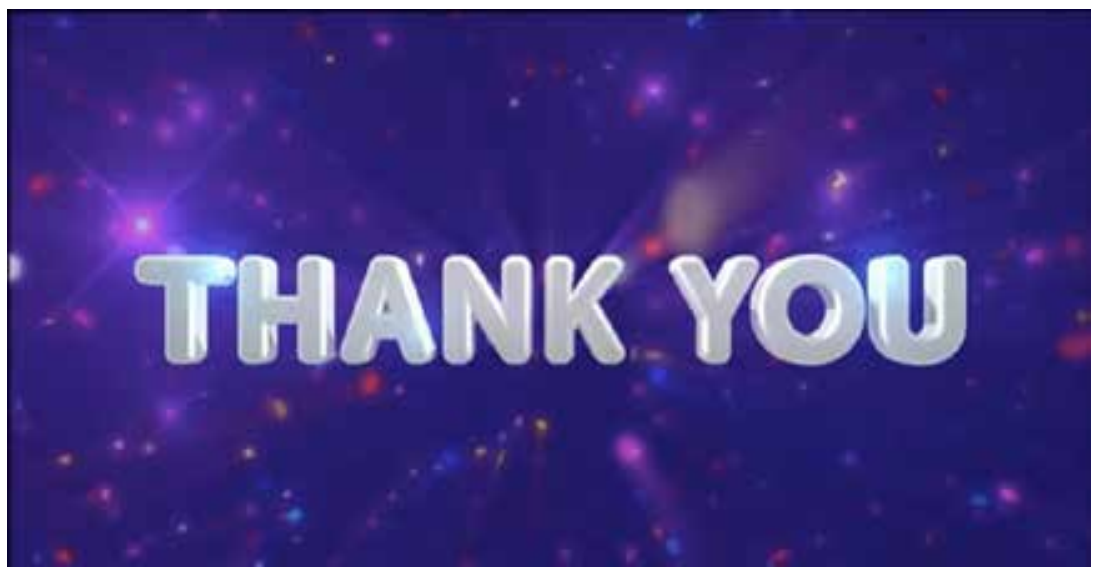

2.6. Children in Need, 13 November 2015, BBC1.

\section{Currency as Aesthetic Strategy: The Campaign Films}

Aside from the wider context of the programme and the currency that underpins the financial basis of the BBC itself, it is also possible to identify a currency at work in the campaign films.

\section{Campaign Film (1): 'Robbie and Rosie's Story', Robin House, Scotland}

In the 2015 film concerning Robin House (located near Balloch in Scotland), the audience is witness to tragedy - the loss of two children by the same parents, Mark and Ann. Their children, Robbie and Rosie, are both diagnosed with the same hereditary life-limiting condition-Infant Battens Disease. The short film is introduced via a direct address from the Scottish actor David Tennant, and it provides details of Robbie and Rosie's lives from the appearance of their initial well-being to their deterioration and ultimately their death. The hospice, its grounds, activities, and staff are clearly presented as essential to the children's lives and to the continuing resilience of the parents. The short film consists of montages of family photographs of Robbie and Rosie, an interview with Mark and Ann during which they relate the narrative of their births, diagnoses, illness, and death, and other sequences which show Ann visiting one of the bedrooms in the hospice used by Rosie at the time of her death, as well as other kinds of activity involving children and staff at the hospice (Figure 2.7).

After relating the suffering and death of Robbie and Rosie, the story is concluded with a happy ending — of sorts — as we witness in the final reveal 


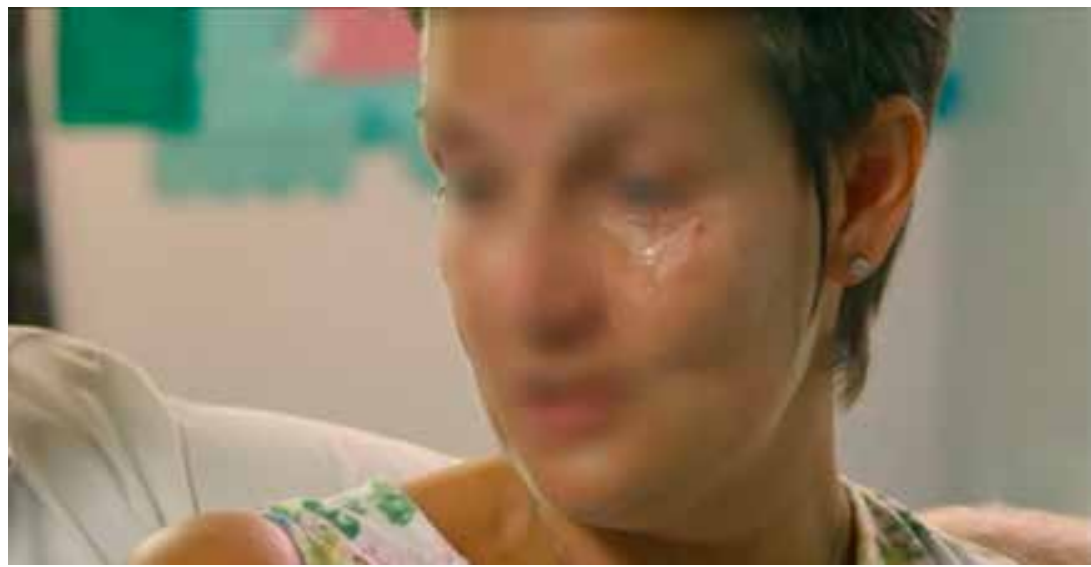

2.7. 'Robbie and Rosie's Story', from Children in Need, 13 November 2015, BBC1.

that Mark and Ann have been able to have two other children (Ruby and Roxy), who are not carriers of the defective gene which caused the life-limiting condition of their siblings. The children do not speak to the camera but are seen playing and interacting with Mark and Ann in the gardens of the hospice. Unsurprisingly, details as to how the beautiful, healthy daughters must have presumably been conceived after extensive screening and medical intervention are not discussed. In the breakdown of the narrative in Table 2.1, we can see that the segmentation of the film provides specific instances through which the audience will anticipate and then experience moments of intense emotion, such as Ann's tears as she recalls the death of Rosie at the hospice.

\section{Campaign Film (2): 'Vanessa's Story', Great Ormand Street Hospital and} the 'Raise a Smile' Foundation, London

Broadcast in November 2017, 'Vanessa's story' details the short life of a young girl suffering from neuroblastoma, a rare and aggressive form of cancer. The film is introduced and narrated by the British actor Olivia Coleman. We first meet Vanessa (in a short sequence recorded in 2012) when she has already been diagnosed with cancer (Figure 2.8).

From there, we are taken through a relatively compressed montage indicative of her various treatments and are provided with two key instances of charitable intervention, in the form of visits from two different female singers from the 'Raise a Smile' foundation who engage with and facilitate Vanessa's love of singing. We hear Vanessa singing short sequences from a couple of keenly emotional songs - 'On My Own' from the West End musical, Les Miserables and ABBA's 'Thank you for the Music' (Figure 2.9). 


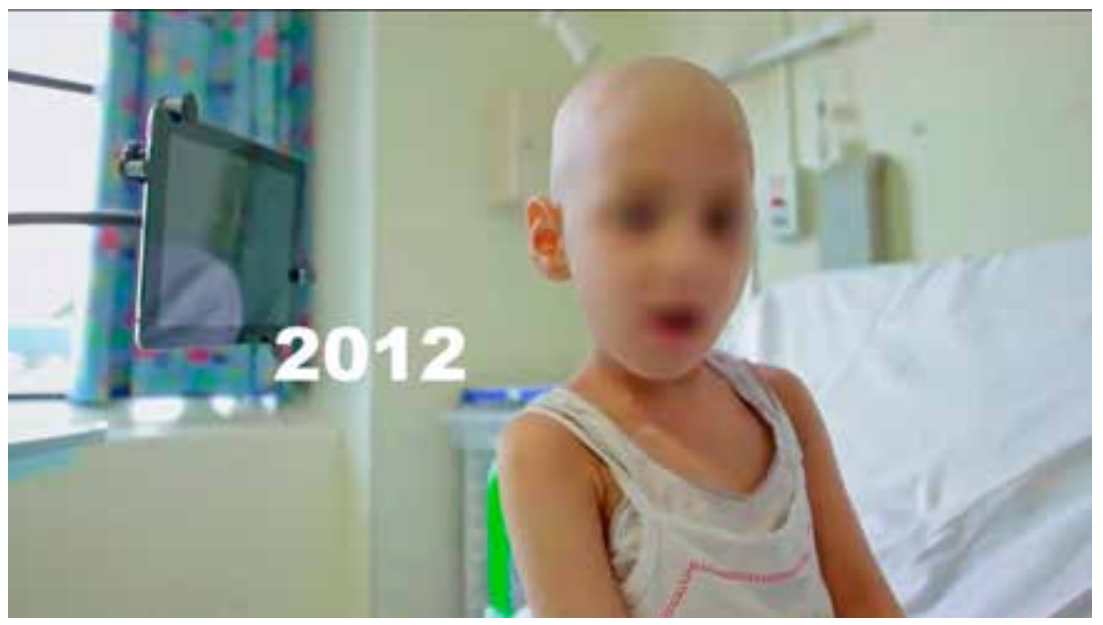

2.8. 'Vanessa's Story', from Children in Need, 17 November 2017, BBC1.

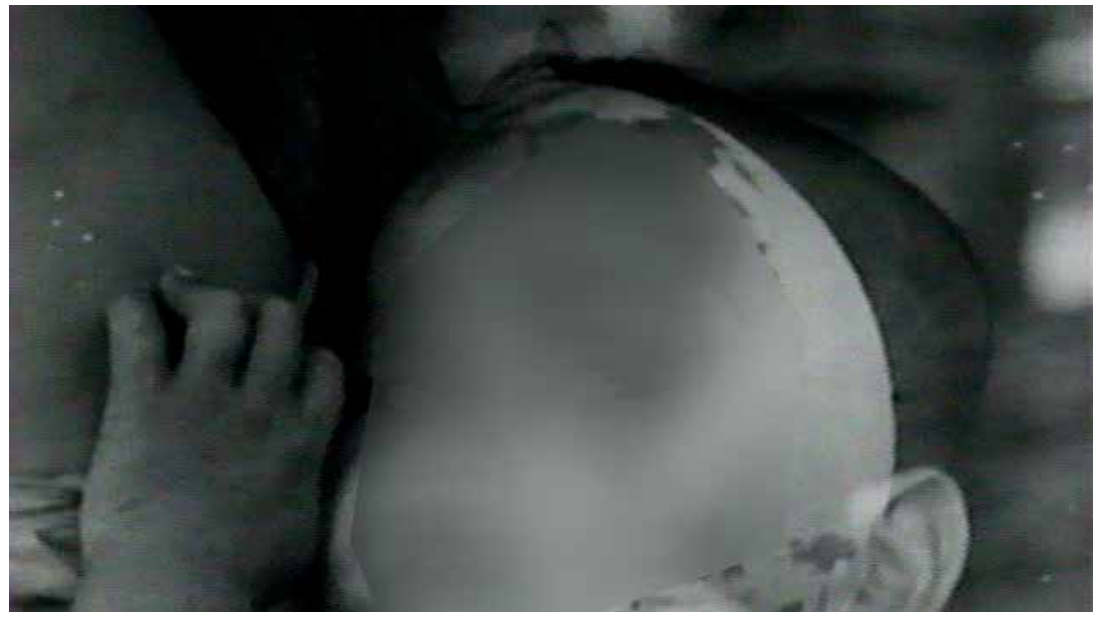

2.9. 'Vanessa's Story', from Children in Need, 17 November 2017, BBC1.

At another point in the film, we see her threading beads onto a necklace with her mother, and the voice-over informs us that each bead represents a new procedure in her care. Vanessa and her mother explain that the four large blue beads on the necklace refer to the four times she has lost her hair over the course of her treatment. Most of the filming takes place in hospital. Vanessa explains at one point that, while she lives in the hospital, her sisters live at home and we see her share a family meal with them via FaceTime or Skype on a computer screen in Vanessa's hospital room. Towards the end of the film, we are told that, in the summer of 2017 (therefore, three 
of four months before the television broadcast), Vanessa is offered one last trial treatment and we witness her hair being shaved (again in hospital). We are then told that, as this treatment fails, on 5 September 2017, two months before the broadcast of the telethon, Vanessa leaves the hospital. We then witness - on what appears to be a handheld camera-Vanessa singing and dancing in school uniform in a classroom context (it is not made entirely clear, however, when or where this footage is taken). An intertitle-a black background with the text in white-then informs us that Vanessa died 'the next day' (on 6 September 2017). The film concludes with a brief sequence in which we return to the previously seen, handheld footage of Vanessa in her school uniform. Vanessa moves in close to the camera, smiling.

\section{Palliative Care Currency: A Developing Model}

Having established the segmented narrative structure of the campaign films (Tables 2.1 and 2.2), we can now compare these with a proposed template for a 'specialist palliative care currency' for children with life-threatening conditions. While this template is in development, the model it articulates aligns directly with the kinds of funding models preferred by the current government, as evidenced in the following recent debate in the House of Lords, where, after a series of interventions, the Conservative Parliamentary Under-Secretary of State, for the Department of Health, Lord O'Shaughnessy, responded:

The noble Baroness, Lady Walmsley, asked about care currencies. She was quite right about the tendency to jargon in this area; it is described as a specialist palliative care currency model, I am afraid, so it is worse than she feared. But the idea is a good one-she highlighted the importance of it - which is to provide a level of transparency and certainty on the kind of funding that will follow. It will not be precisely payment by results or payment by outcome, because of the importance of the charitable sector, but it will provide greater transparency and certainty on the funding of hospices. We aim to publish that shortly. ${ }^{25}$

In Figure 2.10, we can see that, as an exemplar, a child (a boy aged eleven years) has been diagnosed with neoplasms. His care, or the story of his 


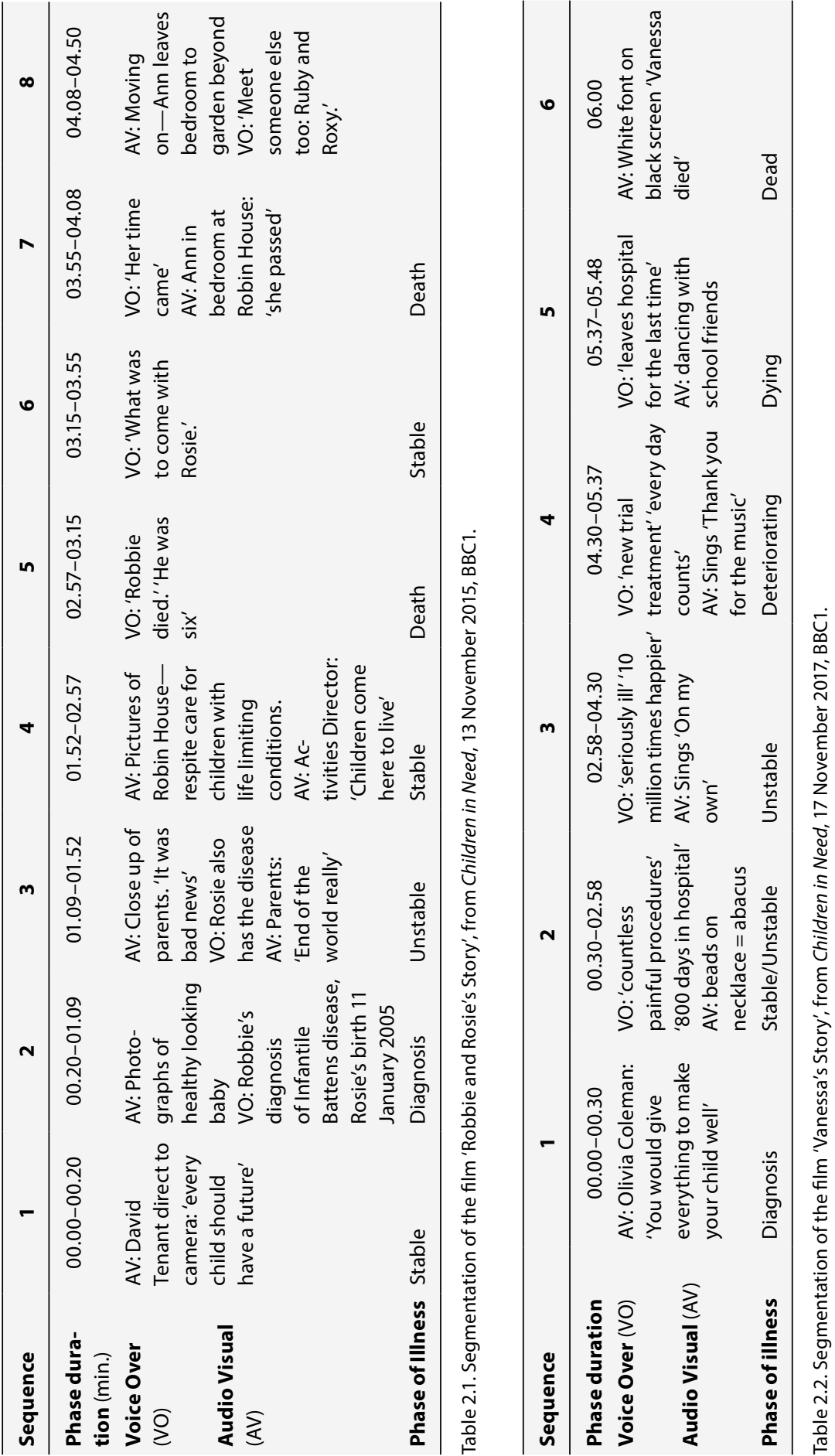




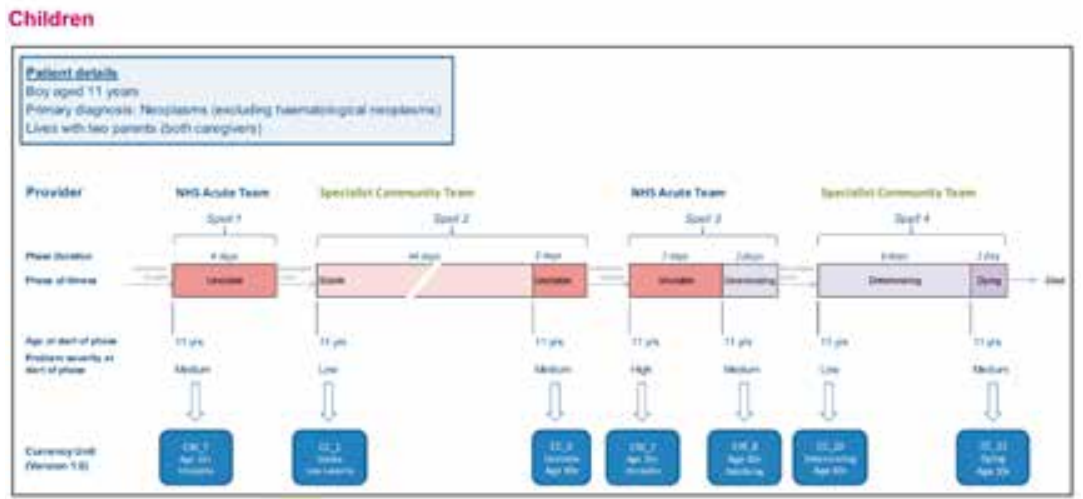

2.10. Annex 9: Palliative Care Currency Case Studies from NHS England, Guidance, p. 39.

illness, is then mapped and segmented into spells and phases during which he is under the care of particular types of nursing provision, either the 'NHS acute team' or the 'specialist community team'. It is likely that this 'specialist community team' will include provision from the children's hospice, which, as already noted, is largely dependent on charitable funding. One of more phases (days) of his illness and treatment are bundled into these 'spells' of care. Each phase of care begins with a calculation of the extent (low/medium/high) of his 'problem severity'. This rises or falls dependent on the perceived stability of the child (which, in itself, is guided by a number of related factors such as pain, physical symptoms, psychological and spiritual problems, carer and/or family concerns). These factors are then rationalized to estimate and award a value to the currency units that are associated with each spell of care the child receives. In this instance, the report explains: 'Currency is the word that is given to a consistent unit of healthcare which can form the basis of payment for that service. ${ }^{26}$ As an example of how the currency model is usually most effective, the report references a routine procedure such as a tonsillectomy. In other words, the currency model is most effective when the medical intervention has a clear procedure and defined outcomes and it is not, as might be the case in relation to an individual child with a life-limiting condition, potentially skewed by a wide range of social, medical, and psychological complexities. Within an associated report-Guidance for Using the Children's Palliative Care Currency -in which pilot studies were 
executed in relation to both adult and child contexts of palliative care, this is acknowledged:

There's not a one size fits all —-The language is appropriate to adults, but less so for children's. A child's trajectory is likely to be very different, even in 2 children with the same condition. However, specialist palliative care, adult oncology patients' journeys can be very similar (and almost textbook). ${ }^{27}$

The deep contradiction here, of course, is that the notion of currency is premised precisely on the fact that, whatever vagaries there may be in their initial quantification, numerical values (the units of currency) are meant to represent robust, objective, and scientific evidence as opposed to discursive or qualitative values that are seen to represent evidence that is dangerously subjective, variable, and anecdotal.

At the time of writing - and from the discussion evident in these recent reports-it is acknowledged that more work (and, of course, given the ideology underpinning the enterprise, more data collection) needs to be done. Equally, there appears to be no real-world context in which the virtual currency being promoted here has been in use so far. As the reports evidence, it has been piloted but not yet mandated. As yet, then, this specific healthcare currency has not been used as way of pricing and allocating funds within the NHS.

Nonetheless, the language of both reports suggests that it will ultimately be adopted: Throughout each report, the need for the currency is emphasized with the promise that it will provide robust evidence for discussions between 'providers and commissioners' and that it will 'provide the evidence base to support discussions on payment. ${ }^{28}$ Clearly, the model speaks directly to the current ideology of neoliberalism: an ideology that derives its legitimacy via the data-driven - and extraordinarily complex - models of both personalization and financialization. As such, the 'health care currency' is likely to remain a focus in the current context where the allocation of NHS funds (how much, for whom, and where) is under intense scrutiny.

As should be clear from the examples given above, the various campaign films shown across the Children in Need telethon have-in part due to their

27 NHS England, Guidance, p. 25. This is one of two guidance documents to support the Development of a New Approach to Palliative Care Funding-Final Report 2015/16 Testing, made available to organizations who wish to use the currencies to support commissioning of Specialist Palliative Care services for adults and children.

28 NHS England, Guidance, p. 11. 
ubiquity and familiarity - also established a very similar kind of currency model. The segmented narratives of the campaign films depend upon agreed (or tried and tested) units that are understood to have a particular weight in relation to their meaning and sentimental value and certain 'sequences' in the campaign film might be aligned with the 'spells' of care that feature in the NHS currency template. That is, each 'sequence' in the film provides a familiar co-incidence of sound and image and this will prompt a specific response, or estimation of its monetary value, just as each 'spell' of care is identified as having a specific numerical value in the NHS currency. As I have described, in the most typical examples, some of the film will be taken up with a photomontage of happier days, although the audience will anticipate the moment when a melancholic song plays as the child inevitably deteriorates. This is the point at which the camera often moves in closer to capture the tearful testimony of parents and siblings, or where we watch as the parents embrace the ailing child on their lap, or stroke their hair or hands as they lie in a hospital or hospice bed. There may also be instances in which the child is appealing directly to the camera, looking through the 'fourth wall' of the camera lens to the audience at home. These 'units' of high emotion - such as tears, lip wobbles, resigned expressions, moments of tender touching, hair stroking, cuddles, or direct eye contact-are not so dissimilar from the moments described by Laura Grindstaff, in her study of US 'reality chat shows' as the 'money shot'. The 'money shot' is the moment when the television cameras successfully capture an instance of extreme emotional outrage or upset from guests. ${ }^{29}$ Children in Need viewers who are prompted to donate money in relation to the films' empathetic cues - sequences in which emotions run high — are acting in response to the successful execution of these narratives' 'money shots'.

What I have deliberately underplayed in my summary analysis of both films is their sincere emotional content. Undoubtedly, the audience's emotional responses will be amplified by the use of music, familiar domestic snapshots, and the use of close-ups, as well as the inclusion of the sometimes tearful but brave testimonies of the children's parents and siblings. These are real children and real families. My analysis is not intended to belittle the suffering of these particular children or to cast doubt on the intentions of the parents, caregivers, charity workers, or film-makers. It does not undermine my argument to insist that each film depends upon the very real and individual personalities and situations of the families and

29 The term 'money shot' is also used in relation to the capturing of male ejaculation in pornography. 


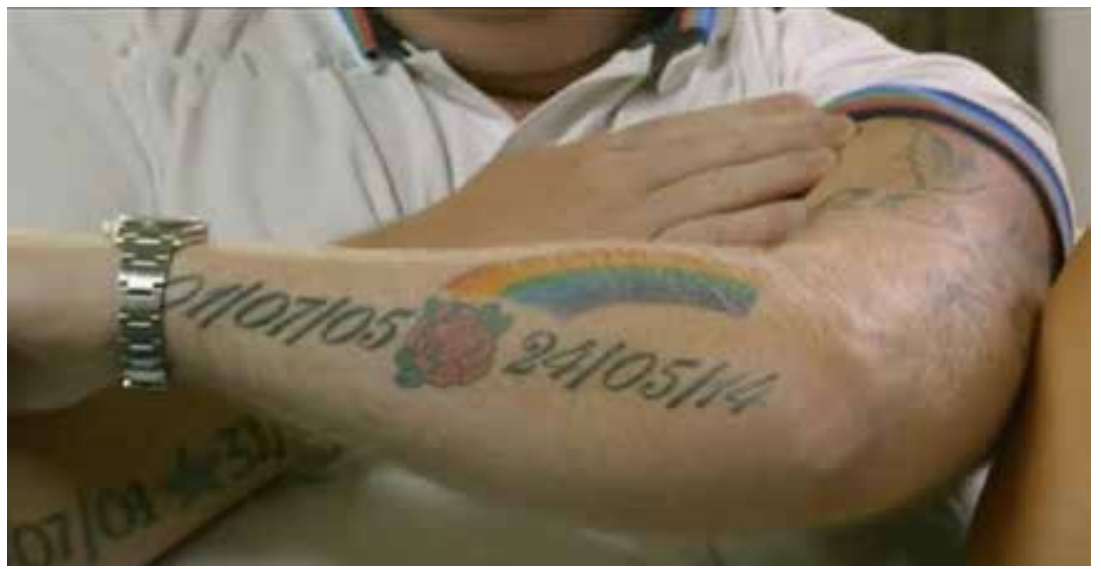

2.11. 'Robbie and Rosie's Story', from Children in Need, 13 November 2015, BBC1.

children involved. In terms of the ethics of the films and the question of the children's consent, in the first film discussed, from 2015, due to the fact that they have died before filming and the nature of their condition, it is unlikely that either Robbie or Rosie could have given any kind of informed consent as to their inclusion in the broadcast. It is evident that their parents, who speak lovingly for and about them, are fully committed to the telling of their children's stories and are determined to affirm the value of Robin House not only for the children they have lost, but also for their own resilience, as well as the mental well-being of their living daughters. This is further confirmed by a short sequence at the end of this film, during which Mark - the father-discusses his tattoos (Figure 2.11). These large tattoos, which take up each forearm, include the names, the date of the births, and the date of the deaths of Robbie and Rosie. He states, somewhat defiantly, that people are often curious about his tattoos but then are often disturbed or bemused that he has included both their dates of birth and the date of their deaths. 'They are my children' he says, and 'I like talking about them'.

Equally, in the second film I have analysed, Vanessa, who is, in most of the sequences, chatty, alert, and articulate, appears entirely comfortable with being filmed and engages directly — through eye contact as well as through singing and talking - with the film-makers, and she presumably recognizes that there will be additional viewers for her story. Vanessa and her family are unique: Evidently, and, as we are told by Coleman, Vanessa is 'special'. However, I can't help finding an uncanny co-incidence in terms of form, content, and ideology in Vanessa and her mother's attempt at making a coherent narrative out of the 'one after another' of Vanessa's successive medical treatments. The beads on her necklace, referred to earlier, are both touching and touchable, 


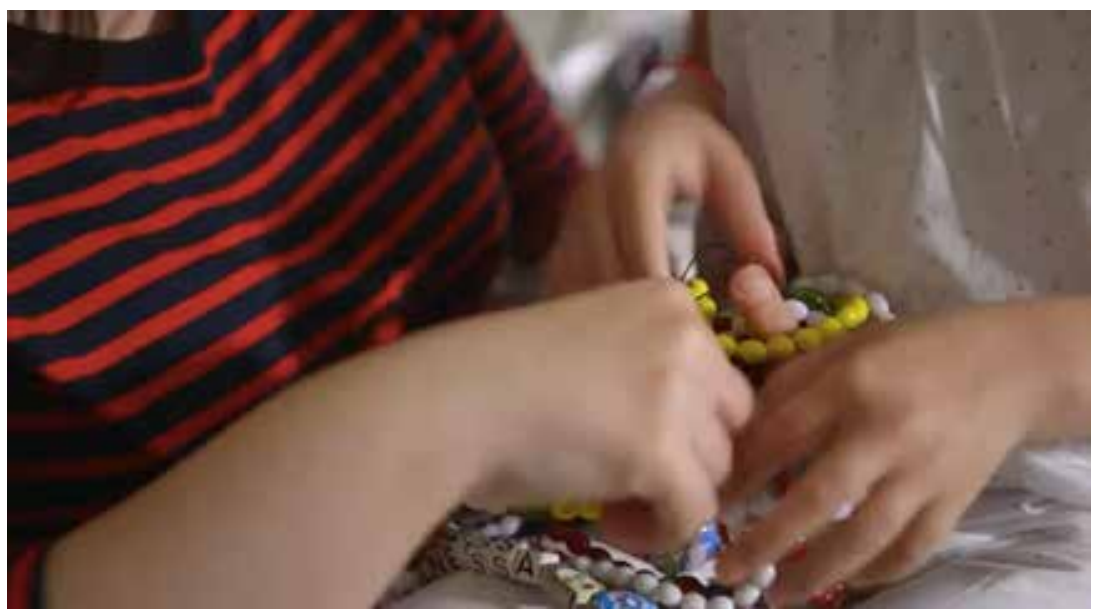

2.12. 'Vanessa's Story', from Children in Need, 17 November 2017, BBC1.

feminized reminders of what were painful and ultimately unsuccessful medical procedures; at the same time and, in the context of my argument, they might also recall beads on an abacus, representing the calculations, numbers, and currency underpinning Vanessa's life story (Figure 2.12).

However sensitive we may want to be to these specific individuals, we cannot escape the sense in which these terminally ill children are incorporated into a broadcast, which is simply one more programme in a long history of similar broadcasts that actively formats their individual life stories into a monetized narrative economy. ${ }^{30}$

\section{Conclusion}

Telethons and their related campaign films are implicated in dismaying assumptions about disability, illness, and the way in which medical care

$3^{0}$ It is beyond the scope of this chapter, but it is worth noting that several British charities have also adopted an explicitly financialized model of legitimating their worth - the Social Return on Investment (SROI) analysis - which 'calculates the social, economic and financial benefits' apparently generated from a £1 donation. For example, a recent SROI analysis was conducted by the consultancy firm Rocket Science for 'The Yard'-a Scottish charity providing an adventure play service for disabled children. (The charity has also featured on Children in Need.) Using evidence from interviews, 'outcomes mapping workshops', and choice modelling, it was calculated that, for every $£_{1}$ invested or donated, the overall 'social return' (in terms of time saved, medical care not required, other care services not requested because of the services) for 'The Yard' could be valued at $£ 20.50$. See The Yard, Social Return on Investment, p. 4. 


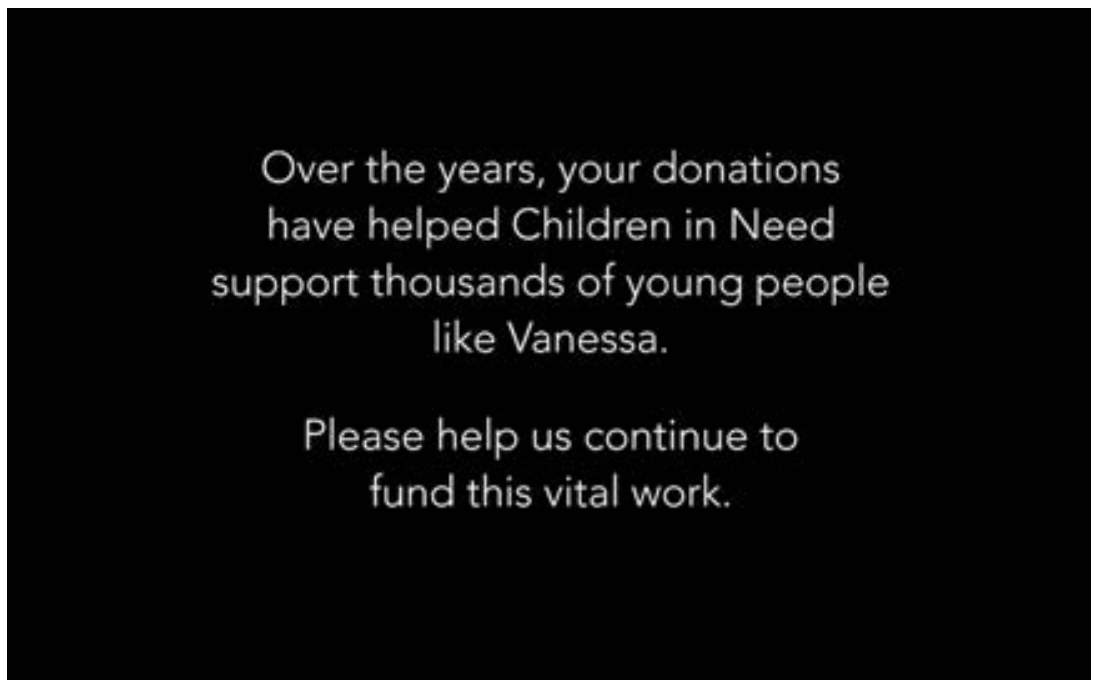

2.13. 'Vanessa's Story', from Children in Need, 17 November 2017, BBC1.

should be managed and financed in contemporary Western society. ${ }^{31}$ In this chapter, however, my purpose was to focus on the significance of financialization and to unpack the mechanics of and units of exchange within the various models of currency at work within the Children in Need broadcast. The first currency model I identified-represented most explicitly by the graphic 'totalizer' representing the incremental amounts of money raised over the evening - is an isolated, meaningless number whose value is asserted primarily in relation to the numerical amount that was raised in previous years. While there may be information provided as to how many children the money has helped (another instance in which numbers are used to 'prove' value), these figures are often very general ('thousands') and there is no wider context given for the money (How many children are not helped?) and no suggestion that funding might be more appropriately derived from taxation, despite the fact that the care supported is understood to be 'vital' (Figure 2.13).

For the BBC, the programme conveniently shores up another currency model (the universal licence fee), which is dependent on the BBC's promise to bring individuals together as 'one' national audience. This alliance between the audience and the nation is bolstered by the programme's promotion of active participation and exhibition by fundraisers. Interestingly, in the policy document by Buck and Wilkinson cited earlier in the chapter, reference is 


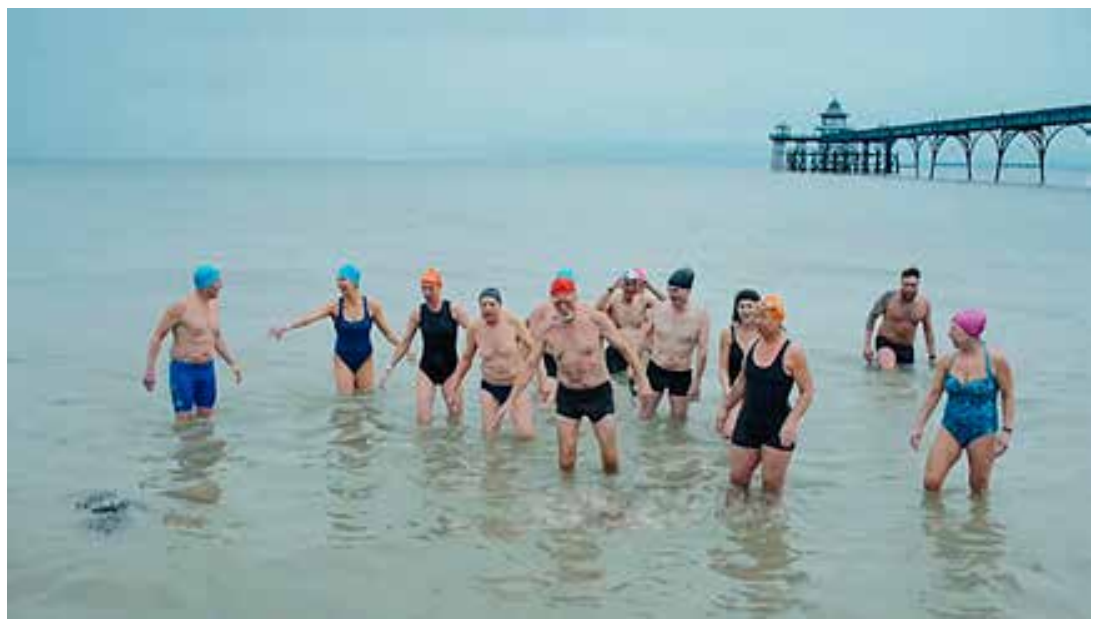

2.14. 'Wild Swimmers', One-ness ident, dir. Martin Parr, 2017, BBC1.

made to the policy at that time of branding of the BBC as 'One BBC'. In 2017, this concept was reimagined as 'One-ness'. Current idents for the channel exemplify the participatory aspects of this concept as they picture a variety of different community groups undertaking various activities, including aerobics, wild swimming, and urban skating (Figure 2.14).

Embedded within the live programme, but necessarily distinct from the pantomime antics of the various stunts that make up the rest of the broadcast, there are a number of pre-recorded charity films that exhibit powerful instances of human suffering. These films are carefully framed, segmented narratives that may also be understood to represent another kind of currency model. However unappealing it may sound, the charity films are undoubtedly carefully organized to provide a series of 'money shots' designed to provoke particular kinds of emotional response and thus donations from the viewing audience. Finally, the currency model of the charity campaign films may then be directly aligned with the 'specialist palliative care currency' currently being piloted as a funding model for the NHS in relation to the care of severely ill children. The narrative segmentation and progress of the dying child in terms of their representation within the medical and broadcast currency models might appear inevitable-in both models, after all, the child dies. However, the significance of their alliance is because the currency model is dependent on the equivalence of 'money' to 'value'. As Mary Poovey argues, the construction of a currency is problematic because money's 'very nature dictates that its value depends on a gap between its material form and the ground of the value it 
supposedly represent $[\mathrm{s}]$ '. ${ }^{2}$ This 'gap' means that the currency model-in both its medical and aesthetic forms - requires the rationalization and homogenization of individuals who are, in reality, unique in terms of their personalities and medical and social needs. Equally, within this currency model, the extent to which certain kinds of medical care already depend on charitable donations is disguised, just as it is underemphasized in the Children in Need broadcast itself.

My focus on currency models has allowed me to illustrate the way in which financialization increasingly underpins the aesthetic strategies of medically significant narratives such as the telethon, that would otherwise appear to provide a context in which the television audience is encouraged to demonstrate unabashed empathy rather than conduct empirically rational valuations as to who is, or isn't, deserving of medical and social care. The increasing colonization of financialization into the wider culture is in line with shifts elsewhere in the charitable sector, as Eve Chiapello observes:

When someone decides to give some money to a charity, or when a local authority decides to award a grant to some social actor, there is always some form of valuation beforehand. First of all, the decision must be made to provide support, and then how much. This valuation operation is what is gradually becoming financialised. ${ }^{33}$

What Children in Need demonstrates is how financialization, or what Chiapello terms as the 'financialisation of valuation' may also be an aesthetic strategy at work within the broadcast itself. The audiovisual operation of the broadcast, and its various generic borrowings, from light entertainment, reality talk shows, pornography, and documentary, illustrates the way in which medical, televisual, and economic discourses are increasingly aligned.

\section{Works Cited}

Films, Television Programmes, and Recordings

Big Brother, Endemol/Channel 4, 2000-2010.

Children in Need, BBC 1980-.

Children in Need: 50 Greatest Moments, BBC, 2010. 
Eastenders, BBC, $1985^{-}$.

The Disney Club, Disney/GMTV, 1993-1998.

The One Show, BBC 2007-.

The X-Factor, SyCoTV/ITV, 2004-.

Top of the Pops, BBC, 1964-2006.

\section{Books and Articles}

Anderson, Benedict, Imagined Communities: Reflections on the Origins and Spread of Nationalism, rev. ed. (London: Verso, 2006).

Boltanski, Luc, Distant Suffering: Morality, Media and Politics, trans. by Graham Burchell (Cambridge: Cambridge University Press, 2005).

Bryant, Christopher G.A., 'National Art and Britain Made Real: The London 2012 Olympics Opening Ceremony', National Identities, 17, 3 (2015), pp. 333-346, doi :10.1080/146o8944.2014.990958.

Buck, Geoff, and Johnny Wilkinson, 'Report for Director of Public Affairs on the Children in Need Appeal' (1986), BBC Written Archives' Centre, archive ref: $\mathrm{R}_{7} 8 / 2 / 633 / 1(10084125)$.

Charlesworth, Diane, 'Stand Up to Cancer 2012 and 2014: The Medical Telethon as UK Public Service Broadcasting in a Neo-Liberal Age', Critical Studies in Television, 11, 2 (2016), pp. 217-229, doi:10.1177/1749602016645750.

Chiapello, Eve, 'Financialisation of Valuation', Human Studies, 38, 1 (2015), pp. 13-35, doi:10.1007/s10746-014-9337-x.

Grindstaff, Laura, The Money Shot: Trash, Class and the Making of TV Talk Shows (Chicago: University of Chicago Press, 2002).

Happer, Catherine, 'Financialisation, Media and Social Change', New Political Economy, 22, 4 (2017), pp. 437-449, doi:10.1080/13563467.2017.1259301.

Heritage, Stuart, 'Children in Need: We'll Miss Terry Wogan but We're in Safe Hands with Dermot O'Leary', The Guardian, 13 November 2015, https://www. theguardian.com/tv-and-radio/tvandradioblog/2015/nov/13/children-in-needwell-miss-terry-wogan-but-were-in-safe-hands-with-dermot-oleary, accessed 24 July 2018.

House of Lords, 'End of Life Care', 14 March 2017, House ofLords Hansard, vol. 779, https://hansard.parliament.uk/Lords/2017-03-14/debates/9EooB6E2-FoD6${ }_{4} \mathrm{D}_{3} \mathrm{~B}-\mathrm{A} 788-\mathrm{A}_{48 \mathrm{~A} 8 \mathrm{~B} 3} \mathrm{FA} 95 \mathrm{D} /$ EndOfLifeCare, accessed 25 July 2018.

Longmore, Paul K., Telethons: Spectacle, Disability and the Business of Charity, ed. by Catherine Kudlick (New York: Oxford University Press, 2016).

NHS England, Guidance for Using the Children's Palliative Care Currency, 22 March 2017, https://www.england.nhs.uk/wp-content/uploads/2017/o3/ guidance-using-childrens-palliative-care-currency.pdf, accessed 25 July 2018. 
Press Association, “Postcode Lottery” Revealed in NHS Care', The Guardian, 8 September 2016, https://www.theguardian.com/society/2016/sep/08/postcodelottery-revealed-in-nhs-care, accessed 25 July 2018.

Children's Hospice Association Scotland, Annual Report and Accounts, 2016-17: For the Year Ended 31 March 2017, https://www.chas.org.uk/about-us/our-vision/ our-publications, accessed 27 August 2018.

Poovey, Mary, Genres of the Credit Economy: Mediating Value in Eighteenth- and Nineteenth-Century Britain (Chicago: University of Chicago Press, 2008).

Timm Knudsen, Britta, and Carsten Stage, Global Media, Biopolitics and Affect: Politicizing Bodily Vulnerability (New York: Routledge, 2015).

The Yard, Social Return on Investment: Technical Report 2016/17, by Clare Hammond with Clara Mascaro and Michael Brown (June 2017), https://www.theyardscotland.org.uk/Handlers/Download.ashx?IDMF=362fo8f6-6049-4d98-b6of9c9bocce5ba4, accessed 26 July 2018.

\section{About the Author}

Karen Lury is Professor of Film and Television Studies in the School of Culture and Creative Arts at the University of Glasgow. She has published in film and television studies, with a particular focus on the representation of the child in film and in relation to children's media more generally. She is currently co-editing a critical anthology for Bloomsbury, entitled, Discourses of Care: Media, Medicine and Society and is a longstanding editor of the international film and television studies journal, Screen.

Contact details: Karen.Lury@glasgow.ac.uk 